2009s-03

\title{
Economic Policy when Models Disagree
}

\author{
Pauline Barrieu \\ Bernard Sinclair-Desgagné
}

\section{Série Scientifique \\ Scientific Series}

\begin{abstract}
Montréal
Août 2009

Ce document est une mise à jour du cahier publié en mars 2009 sous le même numéro
\end{abstract}

(c) 2009 Pauline Barrieu, Bernard Sinclair-Desgagné. Tous droits réservés. All rights reserved. Reproduction partielle permise avec citation du document source, incluant la notice (C).

Short sections may be quoted without explicit permission, if full credit, including $₫$ notice, is given to the source.

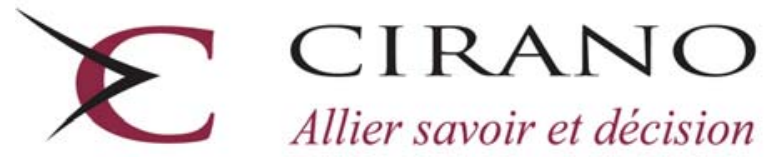

Centre interuniversitaire de recherche en analyse des organisations 


\section{CIRANO}

Le CIRANO est un organisme sans but lucratif constitué en vertu de la Loi des compagnies du Québec. Le financement de son infrastructure et de ses activités de recherche provient des cotisations de ses organisations-membres, d'une subvention d’infrastructure du Ministère du Développement économique et régional et de la Recherche, de même que des subventions et mandats obtenus par ses équipes de recherche.

CIRANO is a private non-profit organization incorporated under the Québec Companies Act. Its infrastructure and research activities are funded through fees paid by member organizations, an infrastructure grant from the Ministère du Développement économique et régional et de la Recherche, and grants and research mandates obtained by its research teams.

\section{Les partenaires du CIRANO}

Partenaire majeur

Ministère du Développement économique, de l'Innovation et de l'Exportation

\section{Partenaires corporatifs}

Banque de développement du Canada

Banque du Canada

Banque Laurentienne du Canada

Banque Nationale du Canada

Banque Royale du Canada

Banque Scotia

Bell Canada

BMO Groupe financier

Caisse de dépôt et placement du Québec

DMR

Fédération des caisses Desjardins du Québec

Gaz de France

Gaz Métro

Hydro-Québec

Industrie Canada

Investissements PSP

Ministère des Finances du Québec

Power Corporation du Canada

Raymond Chabot Grant Thornton

Rio Tinto

State Street Global Advisors

Transat A.T.

Ville de Montréal

\section{Partenaires universitaires}

École Polytechnique de Montréal

HEC Montréal

McGill University

Université Concordia

Université de Montréal

Université de Sherbrooke

Université du Québec

Université du Québec à Montréal

Université Laval

Le CIRANO collabore avec de nombreux centres et chaires de recherche universitaires dont on peut consulter la liste sur son site web.

Les cahiers de la série scientifique (CS) visent à rendre accessibles des résultats de recherche effectuée au CIRANO afin de susciter échanges et commentaires. Ces cahiers sont écrits dans le style des publications scientifiques. Les idées et les opinions émises sont sous l’unique responsabilité des auteurs et ne représentent pas nécessairement les positions du CIRANO ou de ses partenaires.

This paper presents research carried out at CIRANO and aims at encouraging discussion and comment. The observations and viewpoints expressed are the sole responsibility of the authors. They do not necessarily represent positions of CIRANO or its partners. 


\title{
Economic Policy when Models Disagree*
}

\author{
Pauline Barrieu ${ }^{\dagger}$, Bernard Sinclair-Desgagné ${ }^{\ddagger}$
}

\begin{abstract}
Résumé / Abstract
Ce texte propose une nouvelle approche du design des politiques publiques, quand il n'y pas de consensus entre experts sur une représentation adéquate de la situation. Techniquement parlant, nous adoptons pour ce faire une version généralisée de la théorie traditionnelle de la politique économique, telle que développée il y a plusieurs décennies par Jan Tinbergen. Contrairement aux solutions existantes à l'incertitude sur les modèles, notre approche ne demande pas de connaître la fonction d'utilité des décideurs politiques (à l'inverse de la littérature sur l'ambigüité), ni d'avoir un modèle de référence (par contraste avec la théorie du contrôle robuste), ni de posséder une distribution de probabilité sur l'ensemble des scénarios proposés (a contrario de l'approche bayesienne). Nous montrons que les politiques obtenues possèdent plusieurs propriétés que la littérature souvent postule a priori, comme la robustesse et la simplicité.
\end{abstract}

Mots clés : Incertitude sur les modèles, théorie de la politique économique, ambigüité, robustesse

This paper proposes a general way to craft public policy when there is no consensual account of the situation of interest. The design builds on a dual extension of the traditional theory of economic policy. It does not require a representative policymaker's utility function (as in the literature on ambiguity), a reference model (as in robust control theory) or some prior probability distribution over the set of supplied scenarios (as in the Bayesian modelaveraging approach). The obtained policies are shown to be robust and simple in a precise and intuitive sense.

Keywords: Model uncertainty, Theory of economic policy, Ambiguity, Robustness

Codes JEL : D80, E61, C60

\footnotetext{
${ }^{*}$ We are grateful to Olivier Bahn, Arnaud Dragicevic, Claude Henry, Danny Ralph, Stefan Scholtes, and Michel Truchon for helpful conversations and suggestions. We also acknowledge valuable comments from seminar participants at HEC Montréal, the University of Strasbourg, and the Judge Business School/RAND "Modelling for Policy Advice" seminar series at the University of Cambridge. This paper was partly written while SinclairDesgagné was visiting the Judge Business School and the London School of Economics in academic year 20072008.

${ }^{\dagger}$ London School of Economics and Political Science.

${ }^{\ddagger}$ CIRANO and École polytechnique. HEC Montréal, International Economics and Governance Chair, HEC Montréal, 3000 chemin de la Côte-Sainte-Catherine, Montréal, Canada H3T 2A7; e-mail: bsd@hec.ca.
} 
We picture facts to ourselves.

A picture is a model of reality.

- Ludwig Wittgenstein (1922) -

\section{Introduction}

Models are an ever-present input of decision and policy making. Be they very sophisticated or not, they always are partial representations of reality. The same object might therefore admit different models. Well-known current examples include global warming and its various impact assessment models, such as the DICE model conceived by William Nordhaus (1994) and the PAGE model used by Nicholas Stern (2007, 2008), and macroeconomic policy, with its competing DSGE models that respectively build on the New Keynesian framework (see, e.g., Richard Clarida et al., 1999; Michael Woodford 2003) or the Real Business Cycle view (see, e.g., Thomas Cooley 1995). ${ }^{1}$ Due to theoretical gaps, lack of data, measurement problems, undetermined empirical specifications, and the normal prudence of modelers, such episodes of model uncertainty may often last beyond any useful horizon. ${ }^{2}$ Meanwhile, policymakers will be expected to act based on analyses, scenarios and forecasts which can be at variance from each other.

\footnotetext{
1 The "Dynamic Integrated model of Climate and the Economy" (DICE) is a global-economy model that explicitly considers the dynamic relationships between economic activity, greenhouse-gas emissions and climate change. The "Policy Analysis for the Greenhouse Effect" (PAGE), developed by Christopher Hope (2006), generates emission-reduction costs scenarios for four world regions, acknowledging that some key physical and economic parameters can be stochastic. There are many other models addressing the economics of global warming (see, e.g., Alan Manne et al. 1995; Nordhaus and Zili Yang 1996; Nordhaus and Joseph Boyer 2000; and Stern 2007, chapter 6). Most disagreements between climate change modellers have to do with discounting, technological innovation, and the treatment of risk and uncertainty (see, e.g., Geoffrey Heal 2008). Dynamic Stochastic General Equilibrium (DSGE) models, on their part, differ mainly in their microfoundations and the way they capture price and wage adjustments.

2 As Andrew Watson (2008, p. 37) recently pointed out, for instance: "In the foreseeable future (next 20 years) climate modelling research will probably not materially decrease the uncertainty on predictions for the climate of 2100. The uncertainty will only start to decrease as we actually observe what happens to the climate." [Emphasis added]
} 
Economists have recently devoted significant efforts to assist policy making in such circumstances. ${ }^{3}$ Four approaches can be found in the literature at the moment: model averaging, discarding dominated policies, deciding under ambiguity, and robust control. ${ }^{4}$ The first one draws on Bayesian decision theory, thanks in part to new means for constructing prior probability distributions (Adrian Raftery et al. 1997; Gary Chamberlain 2000; Carmen Fernandez et al. 2001; Antoine Billot et al. 2005), and has been advocated by a number of macroeconomists (see Christopher Sims 2002, William Brock et al. 2003, and the references therein). The second route, taken for instance by Charles Manski (2000) for the selection of treatment rules, avoids prior distributions altogether, seeking only policies that cannot be outdone in at least one model. The third approach acknowledges instead that several prior distributions might be plausible at the same time; it then develops decision criteria - such as Itzhak Gilboa and David Schmeidler (1989)'s maximin criterion or the more general adjusted-expected-utility criteria suggested by Zengjing Chen and Larry Epstein (2002), Peter Klibanoff et al. (2005), and Fabio Maccheroni et al. (2006), among others - that fit reasonable patterns of behavior in this case (as they have been documented since Daniel Ellsberg 1961's seminal article). ${ }^{5}$ Robust control, finally, builds

\footnotetext{
${ }^{3}$ The first recognition of the importance of model uncertainty for the evaluation of macroeconomic policy actually dates back to William Brainard (1967).

${ }^{4}$ One might also add exploratory modeling to this list. Pioneered by Steve Bankes (1993), exploratory modeling combines human judgment with systematic interactive computer experiments on a given family of plausible models in order to shed light on policy choices. This approach is currently used in long term policy analysis (see Robert Lempert et al. 2003, for instance). It relies heavily on information technology, but still lacks some economic foundations.

${ }^{5}$ The maximin approach has found numerous applications, notably in finance (see, e.g., Rama Cont 2006, Lorenzo Garlappi et al. 2007, and the references therein).
} 
on engineering (optimal control) methods for finding policies that will put up with any perturbation of a given reference model. ${ }^{6}$ It was persuasively introduced in macroeconomics by Lars Peter Hansen and Thomas Sargent (2001, 2008); some applications also exist in natural resources economics (see, e.g., Catarina Roseta-Palma and Anastasios Xepapadeas 2004).

All these approaches, however, have some drawbacks. As argued for instance by Andrew Levin and John Williams (2003), there might be no single reference model of the economy (since key issues such as expectations formation and inflation persistence are still controversial), which often makes robust control impractical. But the main alternatives - Bayesian model-averaging or multiple-prior decision making - call for probabilistic beliefs over a collection of models or scenarios, which might also prove to be unrealistic in many situations. A major contribution of the recent literature on belief formation has actually been to pin down conditions in which entertaining probabilistic beliefs is hardly achievable or even rational (see the recent survey by Gilboa et al. 2008). ${ }^{7}$ Besides, the available criteria for making decisions under ambiguity remain unsatisfactory: the maximin criterion really corresponds to an extreme form of uncertainty aversion, whereas the more general ones are not yet operational (especially for eliciting and capturing collective

\footnotetext{
${ }^{6}$ In physics, a "perturbation" means a secondary influence on a system that causes it to deviate slightly. Hansen and Sargent (2008) define the word "slightly" as lying within a certain range of the reference model, where distance is measured by an entropy-based metric.

${ }^{7}$ Enriqueta Aragonès et al. (2005) show that complexity, for example, can be one reason for this. A group of experts might also fail to hold a common prior if the set of models or scenarios is sufficiently large (see Martin Cripps et al. 2008).
} 
preferences). Lastly, falling back on undominated policies will not be good enough, for such policies can be numerous and are allowed to do very poorly under some scenarios.

Our goal in this paper is to set out a new approach which avoids these shortcomings. The proposed scheme, which is sketched in Figure 1 and will be formalized in section III, borrows several core elements from Jan Tinbergen (1952)'s theory of economic policy. ${ }^{8}$ In this setting, a model brings together endogenous and exogenous variables, and some policy instruments (the short-term interest rate, say, or a carbon tax). Let different models involving the same policy instruments be simultaneously relevant to policymakers. For initial values of those instruments and the exogenous variables, each model $i=1, \ldots, n$ delivers a (possibly dynamic and stochastic) scenario or forecast $\omega_{i}$. In this context, a policy rule $\Phi$ is a prescription on the utilization of the policy instruments that prompts a revision of all scenarios. The challenge is to design a suitable rule.

\section{Insert Figure 1 about here.}

Suppose that each original scenario $\omega_{i}$ is given a welfare score $u_{i}$ via a mapping $U$, and that the revised scenarios $\omega_{1}^{\prime}, \ldots, \omega_{n}^{\prime}$ must go through an overall policy assessment $\mathrm{v}\left(\omega_{1}^{\prime}, \ldots, \omega_{n}^{\prime}\right)$ expressed in monetary units. Call a policy rule effective if its outcome receives a positive assessment whenever the score of at least one initial scenario falls short of some pre-established objective. We show in Section IV that an effective policy rule exists if and only if a shadow price $\pi\left(u_{1}, \ldots, u_{n}\right)$ can be put on each configuration of scores so that

$$
\mathrm{v} \circ \Phi=\pi \circ U .
$$

\footnotetext{
${ }^{8}$ For an historical perspective, literature review and appraisal, the reader may consult the articles by Andrew Hughes Hallett (1989), Ben van Velthoven (1990), Thráinn Eggertsson (1997), and Nicola Acocella and Giovanni Di Bartolomeo (2007).
} 
This is a straightforward consequence of a generalization of Farkas's Lemma - a statement central to linear programming and convex optimization - due to Bruce Craven (1972). Once an appropriate shadow price schedule $\pi$ is determined, a convenient policy $\Phi$ can then be seeked by solving equation (1).

The scores $u_{i}$ and assessment $\mathrm{v}$ should be regarded as common features of the policy process, as opposed to subjective attributes of an imaginary individual planner. Scores are indeed inherent in rule-based policies such as the Taylor Rule (proposed by John Taylor 1993) or the Kyoto Protocol, where they convey positive or negative deviations from some intended GDP level and inflation rate or some emission reduction target respectively. The assessment $\mathrm{v}$ may reflect the value or merit of policy outcomes to all members of an official board (perhaps following several discussion rounds, as reported for instance by Sims 2002, and Eric Leeper and Sargent 2003). The shadow price $\pi$, on the other hand, can be seen as expressing the policymakers' joint willingness-to-pay for avoiding exposure to uncertain welfare levels in the range $\left\{u_{1}, \ldots, u_{n}\right\}$. Equation (1) thus says that an effective remedy will make the value of its results match the willingness to escape the current situation.

To fix ideas further on this approach, the next section gives a short example of what it can do in comparison to previous methods. The formal framework and general construction of policy rules are then laid out in Sections III and IV respectively. Key economic properties of these rules - such as self-restraint, non-neutrality, holism, robustness, and simpleness - are shown and discussed in Section V; note that these attributes are not postulated ex ante but are derived from the construction. Section VI finally concludes with further remarks on the implementation and some extensions of the proposed scheme. 


\section{An Example}

Suppose there are two models of the economy, none of which is accepted as a benchmark. ${ }^{9}$ Each model $i=1,2$ generates forecasts of aggregate wealth which take the form of normal distributions $N\left(a_{i}-z ;(1-z) \sigma_{i}^{2}\right)$ with mean $a_{i}-z$ and variance $(1-z) \sigma_{i}^{2}$. The parameters $a_{i}$ and $\sigma_{i}^{2}$ are exogenous and specific to each model. The variable $z$, which is scaled so as to belong to the interval $[0,1]$, refers to variance-reducing policies that cost one unit of wealth per unit of decrease in volatility. Let $a_{1}>a_{2}$ and $\sigma_{1}^{2}>\sigma_{2}^{2}$, so the first model reckons a larger average wealth but also greater volatility for any given policy $z$.

In order to apply the undominated-policies and model-averaging approaches, assume the policymakers' preferences over wealth are representable using the constant-absoluterisk-aversion (CARA) utility function $u(x)=-e^{-\alpha x}$ with coefficient of absolute risk aversion $\alpha$. It is well-known that ranking the forecasts of models $i=1,2$ based on the expected values of a CARA utility function amounts to comparing the certainty equivalents

$$
C E_{i}(z)=a_{i}-z-\alpha \frac{(1-z) \sigma_{i}^{2}}{2}=\left(a_{i}-\alpha \frac{\sigma_{i}^{2}}{2}\right)+z\left(\alpha \frac{\sigma_{i}^{2}}{2}-1\right), \quad i=1,2 .
$$

Undominated policies will then generally take the form $z=1$ (if $\alpha \frac{\sigma_{i}^{2}}{2}>1$ for some $i$ ) or $z=0$ (if $\alpha \frac{\sigma_{i}^{2}}{2}<1$ for some $i$ ). Alternatively, a Bayesian policy maker who holds that model 1 is right with prior probability $p$ will choose $z$ to maximize

$$
p C E_{1}(z)+(1-p) C E_{2}(z)=z\left[p \alpha \frac{\sigma_{1}^{2}}{2}+(1-p) \alpha \frac{\sigma_{2}^{2}}{2}-1\right]+\text { a constant }
$$

\footnotetext{
${ }^{9}$ This example is purely illustrative and has no pretence of realism.
} 
and be thereby led to select $z=0$ or 1 . When $\alpha \frac{\sigma_{1}^{2}}{2}>a_{1}>1$ and $\alpha \frac{\sigma_{2}^{2}}{2}<1<a_{2}$, however, such dichotomous policies will perform rather poorly under one model. ${ }^{10}$

In the latter case, by contrast, the maximin policy $z^{*}$ sits at the intersection of the curves $C E_{1}(z)$ and $C E_{2}(z)$, for any set of priors that includes $p \approx 1$ and $p \approx 0$. This action certainly limits the policy maker's exposure to regrettable expected-utility outcomes if either scenario turns out to be the wrong one. But it may seem overly cautious to several people, especially if one model prefigures a very large return from modifying $z^{*}$ slightly.

Turning now to this paper's approach, consider for simplicity the situation depicted in Figure 2, where $C E_{1}\left(z^{*}\right)>-a_{1}+\alpha \frac{\sigma_{1}^{2}}{2}$.

\section{Insert Figure 2 about here.}

Suppose $z=0$ is the current policy, so the initial forecasts are in fact $\omega_{i}=N\left(a_{i} ; \sigma_{i}^{2}\right)$. Ascribe the welfare scores $u_{i}=a_{i}-\alpha \frac{\sigma_{i}^{2}}{2}$ to these forecasts; let the revised scenarios be $\omega_{i}^{\prime}=N\left(a_{i}-z ;(1-z) \sigma_{i}^{2}\right) ;$ and take

$$
\mathrm{v}\left(\omega_{1}^{\prime}, \omega_{2}^{\prime}\right)=\min \left[a_{1}-z-\alpha \frac{(1-z) \sigma_{1}^{2}}{2}, a_{2}-z-\alpha \frac{(1-z) \sigma_{2}^{2}}{2}\right]
$$

as the ex post policy assessments. If the function

$$
\pi\left(u_{1}, u_{2}\right)=-\min \left[u_{1}, u_{2}\right]
$$

captures the policymakers' combined willingness-to-pay to avoid the existing welfare pos-

sibilities $\left\{u_{1}, u_{2}\right\}$, then solving equation (1) amounts to seeking a policy $z^{\bullet}$ such that

$$
\min \left[a_{1}-z^{\bullet}-\alpha \frac{\left(1-z^{\bullet}\right) \sigma_{1}^{2}}{2}, a_{2}-z^{\bullet}-\alpha \frac{\left(1-z^{\bullet}\right) \sigma_{2}^{2}}{2}\right]=-\min \left[a_{1}-\alpha \frac{\sigma_{1}^{2}}{2}, a_{2}-\alpha \frac{\sigma_{2}^{2}}{2}\right]
$$

\footnotetext{
${ }^{10}$ Obviously, the recommended policies took values 0 or 1 because we assumed the cost of policy was linear. Supposing instead a convex cost $c(z)$ could have resulted in solutions $0<z<1$, but the contrasts we want to emphasize with these standard approaches to model uncertainty would then fade away.
} 
This yields two candidates $z_{A}^{\bullet}$ and $z_{B}^{\bullet}$. These policies will not do as well as $z^{*}$ in the worst case, of course. But their respective return will never be inferior to the policymakers' subjective quote $\pi\left(u_{1}, u_{2}\right)$ to escape the current uncertain situation. In the above figure, moreover, $z_{B}^{\bullet}$ produces a much higher reward than $z^{*}$ if model 1 turns out to be right.

Policies like $z_{A}^{\bullet}$ and $z_{B}^{\bullet}$ could have been generated as well through the maximin approach, using a specific set of priors that excludes $p=0$ and $p=1$, or invoking one of the recent criteria for decision making under ambiguity. Our method, however, does not involve a selection of prior distributions (which might have required an infinite regress in beliefs) or an exact encoding of ambiguity aversion. The scores $u_{i}$ and policy evaluations $\mathrm{v}\left(\omega_{1}^{\prime}, \omega_{2}^{\prime}\right)$, moreover, should be viewed as directly observable components of the policy process that do not need to be traced back to a particular utility function. We shall reflect further on this in the upcoming sections, where we make our construction more general and rigorous.

\section{The Basic Framework}

Consider an expert or model $m$ which brings together some exogenous parameters $\tau \in$ $\Upsilon$, policy (or control) variables $z \in Z$ and endogenous variables $x(z, \tau) \in X$. At each specific instances of $\tau$ and $z$, this model generates a scenario or forecast $\omega=m(x(z, \tau), z ; \tau)$ which belongs to a set $\Omega$. There is a total preorder over $\Omega$, denoted $\lesssim$, which corresponds to the policymakers' preferences over all scenarios: for any two scenarios $\omega$ and $\mathrm{w}$ in $\Omega$, $\omega \lesssim \mathrm{w}$ means that $\mathrm{w}$ is "preferable" to $\omega$ from the policymakers' viewpoint. ${ }^{11}$ Let the

\footnotetext{
${ }^{11}$ Recall that a binary relation $\lesssim$ defined over the set $\Omega$ is a total preorder if, for all $\omega, \mathrm{w}, \mathrm{w}^{\circ} \in \Omega$, (i)
} 
function $u: \Omega \rightarrow \mathbb{R}$ represent the policymakers' preferences on a numerical scale, i.e. $\omega \lesssim$ $\mathrm{w}$ if and only if $u(\omega) \leq u(\mathrm{w})$.

\section{A. Multiple-Scenario Assessments}

From now on, there will be $n>1$ different models, denoted $m_{1}, \ldots, m_{n}$, drawn from a set $M$. At a given time, policymakers are then presented a variety of forecasts $\bar{\omega}=$ $\left(\omega_{1}, \omega_{2}, \ldots, \omega_{n}\right)$ which belong to the cartesian product $\Omega^{n} ;$ for $i=1, \ldots n$, we have that $\omega_{i}=m_{i}\left(x_{i}\left(z, \tau_{i}\right), z ; \tau_{i}\right)$, so all models feature the same policy variables (but not necessarily the same exogenous parameters, endogenous variables, or even relationships and structure linking variables and parameters). The preorder relation $\lesssim$ can be applied componentwise to obtain the canonical preorder $\preceq$ on $\Omega^{n}:{ }^{12}$

$$
\bar{\omega} \preceq \overline{\mathrm{w}} \quad \text { if and only if } \omega_{i} \lesssim \mathrm{w}_{i} \text { for all } i=1, \ldots, n \text {. }
$$

If $\omega_{i}<\mathrm{w}_{i}$ for all $i=1, \ldots, n$, we write $\bar{\omega} \prec \overline{\mathrm{w}}$. One can also construct the assessment function $U: \Omega^{n} \rightarrow \mathbb{R}^{n}$ as $U(\bar{\omega})=\left(u\left(\omega_{1}\right), \ldots, u\left(\omega_{n}\right)\right)=\left(u_{1}, \ldots, u_{n}\right)$. Let $\Sigma=U\left(\Omega^{n}\right) \subseteq \mathbb{R}^{n}$ denote the image of $U$; the function $U: \Omega^{n} \rightarrow \Sigma$ is then surjective, by definition.

\section{B. Policy Rules}

Without loss of generality, the number 0 will be seen as a threshold or target for policy. Let $\Sigma_{-}=\Sigma \backslash \mathbb{R}_{+}^{n}=\left\{\bar{u}=\left(u_{1}, \ldots, u_{n}\right) \in \Sigma: u_{i}<0\right.$ for some $\left.i\right\}$, supposing that $\Sigma_{-}$is

either $\omega \lesssim \mathrm{w}$ or $\mathrm{w} \lesssim \omega$ (completeness property), (ii) $\omega \lesssim \omega$ (reflexivity), and (iii) $\omega \lesssim \mathrm{w}$ and $\mathrm{w} \lesssim \mathrm{w}^{\circ}$ implies $\omega \lesssim \mathrm{w}^{\circ}$ (transitivity). When $\omega \lesssim \mathrm{w}$ and $\mathrm{w} \lesssim \omega$, one usually writes $\mathrm{w} \sim \omega$, meaning that $\mathrm{w}$ is "equivalent" to $\omega$ from the policymakers' viewpoint. When $\omega \lesssim \mathrm{w}$ but not $\mathrm{w} \lesssim \omega$, we write $\omega<\mathrm{w}$.

${ }^{12} \mathrm{~A}$ more general framework would have several sets $\Omega_{i}$ with respective complete preorder $\lesssim_{i}, i=1, \ldots, n$ (meaning that the range of possible forecasts and their ranking may depend on who the underlying model or expert is), while the function $u$ takes values in a completely preordered (not necessarily numerical) set. The results shown below are still valid under these extensions. 
nonempty and strictly included in $\Sigma$; each element of the set $\Omega_{-}^{n}=U^{-1}\left(\Sigma_{-}\right)$thus contains at least one scenario policymakers deem bad enough to warrant some remedial action.

Assume that a single action $z^{\prime}$ (which may itself involve the simultaneous or sequential deployment of several policy instruments) is undertaken at a given time, and that each expert or model $i$ is able in this case to provide a revised scenario $\omega_{i}^{\prime}=m_{i}\left(x_{i}\left(z^{\prime}, \tau_{i}\right), z^{\prime} ; \tau_{i}\right)$. Policy intervention can then be portrayed as a function $\Phi: \Omega^{n} \rightarrow \Omega^{n}$ such that $\Phi(\bar{\omega})=\bar{\omega}^{\prime}$ captures its impact (according to the same $n$ models) $\bar{\omega}^{\prime}=\left(\omega_{1}^{\prime}, \omega_{2}^{\prime}, \ldots, \omega_{n}^{\prime}\right)$ on all the initial scenarios $\left(\omega_{1}, \omega_{2}, \ldots, \omega_{n}\right)$ comprised in $\bar{\omega}$. In what follows, we refer to $\Phi$ as a policy rule.

\section{Policy Evaluation}

Modified scenarios and forecasts are ultimately subject to overall appraisals. These are given by the function v: $\Omega^{n} \rightarrow Q$, where $Q$ is a set of real numbers. Below, we denote $Q_{+}$the intersection $Q \cap \mathbb{R}_{+}$, and we assume that $Q_{+}$is a nonempty strict subset of $Q$.

In their account of monetary policy, Levin and Williams (2003, p. 946) report that a policymaking committee usually seeks policy outcomes that are acceptable to all its members. In agreement with this stylized fact, the function $\mathrm{v}$ will be supposed to meet the following assumption.

Assumption 1 (Unanimity). $\bar{\omega} \in \Omega_{-}^{n} \Leftrightarrow \mathrm{v}(\bar{\omega}) \leq 0$.

In other words, policies that perform very poorly in at least one of the committee members' model, and thus fail to be consensual, will receive a nonpositive score. Let $G: \Omega^{n} \rightarrow Q$ denote the composition $G=\mathrm{v} \circ \Phi$ of the functions v and $\Phi$. Under Assumption 1, it can be understood as the policymakers' willingness-to-accept a modification of the initial 
scenarios by means of the policy rule $\Phi$. Accordingly, the set $Q$, with generic element $q$, can be seen as a set of quotes.

This completes the background necessary for laying out our general approach to policy design under model uncertainty.

\section{A General Approach for Policy Making}

The foundation of our approach is the following adaptation to the present context and notation of a theorem demonstrated in Craven (1972; theorem 2.1). This theorem is a nonlinear generalization of the well-known Farkas's Lemma of convex analysis.

Theorem: If $U: \Omega^{n} \rightarrow \Sigma$ is surjective, then

$$
\begin{gathered}
U(\bar{\omega})=U(\overline{\mathrm{w}}) \Rightarrow G(\bar{\omega})=G(\overline{\mathrm{w}}) \text { and } \\
U(\bar{\omega}) \in \Sigma_{-} \Rightarrow G(\bar{\omega}) \in Q_{+}
\end{gathered}
$$

for all $\bar{\omega}, \overline{\mathrm{w}} \in \Omega^{n}$ if and only if there exists a function $\pi: \Sigma \rightarrow Q$ such that

$$
G=\pi \circ U \text { and } \pi\left(\Sigma_{-}\right) \subset Q_{+} .
$$

The above framework ensures that the theorem's hypothesis is satisfied. ${ }^{13}$ A policy rule $\Phi$ that fulfills condition (3) can be called effective; it amends any combination of bad scenarios so that no further intervention is needed. Condition (2) is one of consistency: scenarios which get the same rankings trigger equivalent policies (from the policymakers' standpoint). Of course, one may have $\Phi(\bar{\omega}) \neq \Phi(\overline{\mathrm{w}})$ but $G(\bar{\omega})=G(\overline{\mathrm{w}})$, so this condition does not exclude applying different treatments to similar scenarios (as the above example

\footnotetext{
${ }^{13}$ If $\Omega^{n}, \Sigma$ and $Q$ are topological spaces, $U$ is a continuous open map and $G$ is continuous, one can also show that the price schedule $\pi$ must be continuous (see Craven 1972).
} 
illustrates). Condition (2) does not apply to situations where $\overline{\mathrm{w}}$ is a permutation of $\bar{\omega}$, for in this case $U(\bar{\omega}) \neq U(\overline{\mathrm{w}})$ most of the time; the identity of an expert who supports a given scenario may thus matter for policy.

Since $\pi\left(\Sigma_{-}\right) \subset Q_{+}$, so $\pi\left(u_{1}, \ldots, u_{n}\right)$ is positive if an initial assessment $u_{i}$ is bad $\left(u_{i}<0\right.$ for some $i$ ), the "dual" function $\pi$ can be typically interpreted as indicating the "price" policymakers would pay to avoid an original set of potential welfare levels $\left\{u_{1}, \ldots, u_{n}\right\}$. The theorem then says that a consistent and effective policy rule must be such that the policymakers' collective willingness-to-accept its impact $G=\mathrm{v} \circ \Phi$ matches their joint willingness-to-pay $\pi \circ U$ to escape the initial forecasts. The proof of this statement follows. Proof (Craven 1972): Suppose that conditions (2) and (3) are true. Then, for each $\bar{u} \in \Sigma$, let $\pi(\bar{u})=G(\bar{\omega})$, where $\bar{\omega}$ is any element of $\Omega^{n}$ such that $U(\bar{\omega})=\bar{u}$. Condition (2) ensures that $\pi$ is a well-defined function. Furthermore, its domain is $\Sigma$, since $U\left(\Omega^{n}\right)=\Sigma$, and $G=\pi \circ U$ by definition. If $\bar{u} \in \Sigma_{-}$, then $\bar{u}=U(\bar{\omega})$ for some $\bar{\omega} \in \Omega_{-}^{n}$, and (3) entails

$$
U(\bar{\omega}) \in \Sigma_{-} \Rightarrow G(\bar{\omega})=\pi(\bar{u}) \in Q_{+},
$$

so $\pi\left(\Sigma_{-}\right) \subset Q_{+}$. Conversely, let $\pi: \Sigma \rightarrow Q$ satisfy (4); the function $G$ defined as $G=\pi \circ U$ obviously meets (2) and (3).

This theorem justifies seeking a suitable policy $\Phi$ by solving the fundamental equation

$$
\mathrm{v} \circ \Phi=\pi \circ U .
$$

The construction first relies on the mappings $U$ and $\mathrm{v}$, which refer to ex ante and $e x$ post scenario assessments. Such evaluations are at least implicit in any working policy process, and the functions $U$ and $\mathrm{v}$, being general ones, should be able to fit most common practices. The approach also chiefly involves the willingness-to-pay $\pi$. The latter may 
be directly elicited from policymakers, inferred from past policies $\Phi_{\text {past }}$ (solving then the equation $\mathrm{v} \circ \Phi_{\text {past }}=\pi \circ U$ with respect to $\pi$ ), or simply taken so that $-\pi \circ U=\mathrm{v}$ (as in the above example). ${ }^{14}$ Once $U, \mathrm{v}$ and $\pi$ are at hand, one can find $\Phi$ by working out equation (1) directly, as in the example of Section II, or by taking a quasi-inverse $\mathrm{v}^{[-1]}$ of v so that ${ }^{15}$

$$
\Phi=\mathrm{v}^{[-1]} \circ \pi \circ U
$$

To strengthen the present role and interpretation of $\pi$, let us replace the theorem's condition that $\pi\left(\Sigma_{-}\right) \subset Q_{+}$with the following stronger requirement.

Assumption 2 (Strict willingness-to-pay). $\bar{u} \in \Sigma_{-} \Leftrightarrow \pi(\bar{u})>0$.

As we shall now see, policy rules built with shadow prices $\pi$ that satisfy the latter have appealing characteristics.

\section{Some Key Economic Properties of Policy Rules}

The literature on model uncertainty normally stipulates a priori that the designed policy rules possess certain desirable properties. One such property is robustness, which calls for policies that may not be optimal under some models but will be acceptable if any of the ex post scenarios materializes (see, e.g., Hansen and Sargent 2008). Another one is simpleness, which precludes policies from fine-tuning the available models to achieve specific scenarios. This section shows that our approach actually endows the obtained

\footnotetext{
${ }^{14}$ Implementation issues and the elicitation of $\pi$ are further discussed in the concluding section.

${ }^{15}$ The mapping $\mathrm{v}^{[-1]}: Q \rightarrow \Omega^{n}$ is a quasi-inverse of $\mathrm{v}$ if $\mathrm{v} \circ \mathrm{v}^{[-1]} \circ \mathrm{v}=\mathrm{v}$. Every function has a quasi-inverse (if the Axiom of Choice holds). Yet, $\mathrm{v}^{[-1]}$ is not unique unless $\mathrm{v}$ is a bijection. Note that $\mathrm{v}^{[-1]}$ can be a quasi-inverse of $\mathrm{v}$ but not vice versa; this fact must be dealt with in order to use (5).
} 
policy rules with these (and other) valuable properties.

One first pleasing attribute of a policy rule $\Phi$ which solves equation (1) under Assumptions (1) and (2) is that it eliminates all the bad initial scenarios and never induces an unfavorable one. Hence, when a model $i$ initially renders a forecast $\omega_{i}$ such that $u\left(\omega_{i}\right)<0$, nobody would challenge the rule.

Property 1 (Consensual remedy): For all $\bar{\omega} \in \Omega_{-}^{n}, \Phi(\bar{\omega}) \notin \Omega_{-}^{n}$.

Proof: Suppose there exists some $\bar{\omega} \in \Omega_{-}^{n}$ with $\Phi(\bar{\omega}) \in \Omega_{-}^{n}$. By Assumption 1, we must have that $\mathrm{v} \circ \Phi(\bar{\omega}) \leq 0$. However, since $\bar{\omega} \in \Omega_{-}^{n}, U(\bar{\omega}) \in \Sigma_{-}$and $\pi \circ U(\bar{\omega})>0$ by Assumption 2. This contradicts the fact that $\mathrm{v} \circ \Phi(\bar{\omega})=\pi \circ U(\bar{\omega})$.

By contrast, policy intervention will not receive unanimous support when all initial scenarios are good, for it will give rise to at least one bad forecast.

Property 2 (Self-restraint): Let $\Omega_{+}^{n}=\Omega^{n} \backslash \Omega_{-}^{n}$. For all $\bar{\omega} \in \Omega_{+}^{n}, \Phi(\bar{\omega}) \notin \Omega_{+}^{n}$.

Proof: Assume there exists some $\bar{\omega} \in \Omega_{+}^{n}$ with $\Phi(\bar{\omega}) \in \Omega_{+}^{n}$. By Assumption 1, we must have that $\mathrm{v} \circ \Phi(\bar{\omega})>0$. However, since $\bar{\omega} \in \Omega_{+}^{n}, U(\bar{\omega}) \in \Sigma \backslash \Sigma_{-}$and $\pi \circ U(\bar{\omega}) \leq 0$ by Assumption 2. This contradicts the fact that $\mathrm{v} \circ \Phi(\bar{\omega})=\pi \circ U(\bar{\omega})$.

A direct consequence of these properties is that $\Phi$ does not have a fixed point. This means that no policy intervention is without consequences on the ex post scenarios.

Property 3 (Non neutrality): For all $\bar{\omega} \in \Omega^{n}, \Phi(\bar{\omega}) \neq \bar{\omega}$.

This third property may serve as a warning on policymakers to use the policy rule wisely. It may alternatively be viewed as a rough safeguard against indifferent or stubborn experts who would maintain their initial forecast after the policy rule was applied. 
Finally, call an application $\Gamma: \Omega^{n} \rightarrow \Omega^{n}$ decomposable if there are functions $\gamma_{i}: \Omega \rightarrow$ $\Omega, i=1, \ldots, n$, such that $\Gamma(\bar{\omega})=\left(\gamma_{1}\left(\omega_{1}\right), \ldots, \gamma_{n}\left(\omega_{n}\right)\right)$ for all $\bar{\omega}=\left(\omega_{1}, \ldots, \omega_{n}\right) \in \Omega^{n} .{ }^{16}$ A policy rule $\Phi$ constructed as above will not have this feature.

Property 4 (Holism): The policy rule $\Phi: \Omega^{n} \rightarrow \Omega^{n}$ is not decomposable.

Proof: Suppose instead that $\Phi(\bar{\omega})=\left(\varphi_{1}\left(\omega_{1}\right), \ldots, \varphi_{n}\left(\omega_{n}\right)\right)$ for all $\bar{\omega}=\left(\omega_{1}, \ldots, \omega_{n}\right) \in \Omega^{n}$. Take now some $\bar{\omega}^{\diamond}=\left(\omega_{1}^{\diamond}, \ldots, \omega_{n}^{\diamond}\right) \in \Omega_{+}^{n}$ so that $u\left(\varphi_{1}\left(\omega_{1}^{\diamond}\right)\right)<0$, and consider an n-tuple $\bar{\omega}^{\nabla}=\left(\omega_{1}^{\diamond}, \omega_{2}, \ldots, \omega_{n}\right)$ where $u\left(\omega_{n}\right)<0$. We then have that $\Phi\left(\bar{\omega}^{\nabla}\right)=\left(\varphi_{1}\left(\omega_{1}^{\diamond}\right), \ldots, \varphi_{n}\left(\omega_{n}\right)\right)$ with $\varphi_{1}\left(\omega_{1}^{\diamond}\right)<0$, which contradicts Property 1 .

In concrete terms, Property 4 says that the way a policy intervention determined by $\Phi$ is going to amend an original scenario will depend on all the scenarios initially submitted to policymakers. ${ }^{17}$ This calls attention to the effect an upstream decision (which could be based on strategic, ideological or epistemological considerations) to let a scenario in or not might have on the design of policy.

\section{A. Robustness}

If one is ready to assume that the set $\Omega^{n}$, partially ordered by $\preceq$, is a complete lattice, ${ }^{18}$ Property 3 combined with some fixed-point theorems of lattice theory (see Brian Davey

\footnotetext{
${ }^{16}$ This is a stronger form of decomposability. In mathematics and computer science, the decomposition of a multivalued function $\Gamma: \Omega^{n} \rightarrow \Omega^{n}$ involves some functions $\gamma_{1}, \ldots, \gamma_{n}: \Omega^{n} \rightarrow \Omega$ and $\Lambda: \Omega^{n} \rightarrow \Omega^{n}$ such that $\Gamma(\bar{\omega})=\Lambda\left(\gamma_{1}(\bar{\omega}), \ldots, \gamma_{n}(\bar{\omega})\right)$ for all $\bar{\omega} \in \Omega^{n}$.

${ }^{17}$ This is actually true as well for policies that suit the maximin criterion.

${ }^{18}$ Recall that $\left(\Omega^{n}, \preceq\right)$ is a complete lattice if, in addition to properties (ii) and (iii) listed in footnote 10 , we have that (iv) for all $\bar{\omega}, \overline{\mathrm{w}} \in \Omega^{n}, \bar{\omega} \preceq \overline{\mathrm{w}}$ and $\overline{\mathrm{w}} \preceq \bar{\omega}$ implies $\bar{\omega}=\overline{\mathrm{w}}$ (antisymmetry) and (v) every subset of $\Omega^{n}$ has a least upper bound (supremum) and a greatest lower bound (infimum) in $\Omega^{n}$ (completeness). Property (iv), which makes $\preceq$ an order relation, forbids that two scenarios $\bar{\omega}$ and $\overline{\mathrm{w}}$ be equivalent without being identical (i.e. such that $\bar{\omega}_{i} \sim \overline{\mathrm{w}}_{i}$ for all $i$ ); to satisfy this, one may take $\Omega$ as a set made of collections of equivalent scenarios, each collection being represented by one of its elements.
} 
and Hilary Priestley 2002, theorems 8.22 and 8.23) implies that the policy rule $\Phi$ is neither order-preserving (or monotone) nor all-improving - the latter meaning that $\bar{\omega} \prec \Phi(\bar{\omega})$ for all $\bar{\omega} \in \Omega^{n}$. This characteristic actually holds on the very domain $\Omega_{-}^{n}$ where policy intervention is needed.

PROPERTy 5 (Imperfect enhancement): For at least one $\bar{\omega} \in \Omega_{-}^{n}$, we have that $\bar{\omega} \nprec \Phi(\bar{\omega})$.

Proof: Suppose instead that $\bar{\omega} \prec \Phi(\bar{\omega})$ for all $\bar{\omega} \in \Omega_{-}^{n}$. Let

$$
\Omega_{-}^{\triangleright}=\left\{\bar{\omega}=\left(\omega_{1}, \ldots, \omega_{n}\right) \in \Omega^{n} \mid u\left(\omega_{i}\right)=u_{i}<0 \text { for all } i \neq 1\right\} .
$$

Since $\Omega^{n}$ is a complete lattice, the set $\Omega_{-}^{\triangleright}$ has a supremum $\vee \Omega_{-}^{\triangleright}=\varpi^{\triangleright}=\left(\omega_{1}^{\triangleright}, \ldots, \omega_{n}^{\triangleright}\right)$. Clearly, $u\left(\omega_{i}^{\triangleright}\right)=u_{i}<0$ for all $i \neq 1$, so $\bar{\omega}^{\triangleright} \in \Omega_{-}^{\triangleright}$. Taking $\Phi\left(\widehat{\omega}^{\triangleright}\right)$, consider now the n-tuple $\bar{\omega}^{\triangle}=\left(\Phi_{1}\left(\varpi^{\triangleright}\right), \omega_{2}^{\triangleright}, \ldots, \omega_{n}^{\triangleright}\right)$ which differs from $\varpi^{\triangleright}$ in having the first component of the latter replaced by the first component $\Phi_{1}\left(\vec{\omega}^{\triangleright}\right)$ of $\Phi\left(\vec{\omega}^{\triangleright}\right)$. Such a n-tuple also belongs to $\Omega_{-}^{\triangleright}$, so we must have that $\Phi_{1}\left(\bar{\omega}^{\triangle}\right) \lesssim \omega_{1}^{\triangleright}$. This inequality contradicts our initial assumption.

This property could be observed in the example of Figure 2, where we had $u\left(\omega_{2}^{\prime}\right)=$ $a_{2}-z^{\bullet}-\alpha \frac{\left(1-z^{\bullet}\right) \sigma_{2}^{2}}{2}<a_{2}-\alpha \frac{\sigma_{2}^{2}}{2}=u\left(\omega_{2}\right)$. Together with Property 1, it captures the meaning of robustness: the policy rule $\Phi$ fulfills its objectives in taking care of the unwelcome original scenarios, sometimes at the expense of the good ones (hence in a nonoptimal way with respect to some models), but never to the point of changing the latter into bad ones.

Properties 1 and 5 suggest in addition that solving equation (1) provides a means of crafting precautionary policies. ${ }^{19}$ Reporting on the Federal Reserve Chairman's conference to the 2004 annual meeting of the American Economic Association, Carl Walsh (2004)

\footnotetext{
${ }^{19}$ See Barrieu and Sinclair-Desgagné (2006) for further discussion on this point and the related implementation of the so-called Precautionary Principle.
} 
defined a precautionary policy as one that "would err on the side of reducing the chance that the more costly outcome occurs." Satisfying the maximin criterion was then seen as a practical way to bring about such a policy. Our approach now offers a distinct alternative, which also gives priority, but not exclusive attention, to the worst cases.

\section{B. Simpleness}

Simple policy rules were advocated decades ago by Milton Friedman (1968), considering the complexity of the economy and the ensuing uncertainty of policymakers. In the present context, this requirement can be understood as saying that the range of working policies $Z(\bar{\omega}) \subset Z$ should be narrower (thereby forcing policy rules to be less elaborate), when the number of disagreeing scenarios comprised in $\bar{\omega}$ increases. Our approach will obey this desideratum in at least two occasions.

Property 6, CASE I (Decreasing policy range), Let $\mathrm{v}(\overline{\mathrm{w}})=-1$ if $u\left(\mathrm{w}_{i}\right)<0$ for at least one $i$, and $\mathrm{v}(\overline{\mathrm{w}})=1$ otherwise. Starting with at least one bad scenario, the set of policies for which equation (1) is satisfied decreases with the number of scenarios $n$.

Proof: Take $\bar{\omega}=\left(m_{1}\left(x_{1}\left(z, \tau_{1}\right), z ; \tau_{1}\right), \ldots, m_{n}\left(x_{n}\left(z, \tau_{n}\right), z ; \tau_{n}\right)\right)$ in $\Omega_{-}^{n}$, and denote

$$
Z(\bar{\omega})=\left\{z^{\prime} \mid \mathrm{v}\left(m_{1}\left(x_{1}\left(z^{\prime}, \tau_{1}\right), z^{\prime} ; \tau_{1}\right), \ldots, m_{n}\left(x_{n}\left(z^{\prime}, \tau_{n}\right), z^{\prime} ; \tau_{n}\right)\right)=1\right\}
$$

the set of policies that can then solve equation (1). Consider the augmented family of scenarios $\left(\bar{\omega}, \omega_{n+1}\right)$ where $\omega_{n+1}=m_{n+1}\left(x_{n+1}\left(z, \tau_{n+1}\right), z ; \tau_{n+1}\right)$. This configuration belongs to $\Omega_{-}^{n+1}$ by definition, and the set of successful policies, which is (abusing notation)

$$
Z\left(\bar{\omega}, \omega_{n+1}\right)=\left\{z^{\prime} \mid \mathrm{v}\left(m_{1}, \ldots, m_{n}\left(x_{n}\left(z^{\prime}, \tau_{n}\right), z^{\prime} ; \tau_{n}\right), m_{n+1}\left(x_{n+1}\left(z^{\prime}, \tau_{n+1}\right), z^{\prime} ; \tau_{n+1}\right)\right)=1\right\},
$$

must be a subset of $Z(\bar{\omega})$. 
In other words, when ex post policy appraisals take only two values, as will happen if they express collective decisions to endorse $(\mathrm{v}(\bar{w})=1)$ or disapprove $(\mathrm{v}(\bar{w})=-1)$ all modified configurations of scenarios, greater model uncertainty in circumstances where policy intervention is warranted (according to properties 1 and 2) will reduce the policymakers' options and so make fine-tuned remedies less likely.

To introduce the second case, let

$$
Z_{q, n}(\bar{\omega})=\left\{z^{\prime} \mid \mathrm{v}\left(m_{1}\left(x_{1}\left(z^{\prime}, \tau_{1}\right), z^{\prime} ; \tau_{1}\right), \ldots, m_{n}\left(x_{n}\left(z^{\prime}, \tau_{n}\right), z^{\prime} ; \tau_{n}\right)\right)=q\right\}
$$

be the set of successful actions if $\pi \circ U(\bar{\omega})=q$. A similar conclusion now holds.

Property 6, CASE II (Decreasing policy range): Suppose that (i) $Z_{q^{\prime}, n}(\bar{\omega}) \subset Z_{q, n}(\bar{\omega})$ when $0<q<q^{\prime}$, for all $n$ and $\bar{\omega}$, (ii) $Z_{q, n+1}\left(\bar{\omega}, \omega_{n+1}\right) \subset Z_{q, n}(\bar{\omega})$ for all $n, q,\left(\bar{\omega}, \omega_{n+1}\right)$, and (iii) $\pi$ increases with the relative number of bad scenarios. Then $Z\left(\bar{\omega}, \omega_{n+1}\right) \subset Z(\bar{\omega})$ when $\bar{\omega} \in \Omega_{-}^{n}$ and $u\left(\omega_{n+1}\right)<0$.

Proof: Take $\left(\bar{\omega}, \omega_{n+1}\right)$ such that $\bar{\omega} \in \Omega_{-}^{n}$ and $u\left(\omega_{n+1}\right)<0$. Let $\pi \circ U(\bar{\omega})=q$ and $\pi \circ U\left(\bar{\omega}, \omega_{n+1}\right)=q^{\prime}$. By (iii), we have that $0<q<q^{\prime}$. It now follows that

$$
Z\left(\bar{\omega}, \omega_{n+1}\right)=Z_{q^{\prime}, n+1}\left(\bar{\omega}, \omega_{n+1}\right) \subset Z_{q, n+1}\left(\bar{\omega}, \omega_{n+1}\right) \subset Z_{q, n}(\bar{\omega})=Z(\bar{\omega}),
$$

where the first and second inclusions come respectively from (i) and (ii).

That is, when having to meet a higher willingness to pay (assumption i) or deal with more disagreeing experts (assumption ii) reduces the policymakers' choice, and when the policymakers' collective quote to avoid an initial situation goes up with the proportion of bad scenarios (assumption iii), greater model uncertainty in circumstances where policy intervention is increasingly justified might again induce simpler policy rules. 


\section{Conclusion}

In the presence of model uncertainty, having a policy process that formally assesses and ranks ex ante forecasts and ex post policy outcomes may suffice to develop an effective and consistent policy rule, provided one also knows the policymakers' joint willingness-to-pay to avoid an initial configuration of scenarios. Under unanimous decision making and strict willingness-to-pay, the obtained policy rules will share a number of additional properties, such as self-restraint, robustness and simpleness. These results do not depend on knowing a representative policymaker's probabilitistic beliefs and utility function. They remain valid whether model uncertainty is due to empirical limitations or conflicting paradigms.

This paper's objective was to offer a general framework to design trigger policies when there is no consensual trigger. A worthwhile particular application, for instance, might currently be in the area of banking regulation. Banks and other financial institutions are generally required to hold a minimal capital level to protect deposits against a potential

drop in the value of their assets. It is widely accepted, however, that capital reserves should vary according to a bank's risk exposure: one that heavily invested in highly liquid and very safe securities (such as U.S. government bonds), for example, should not need to keep the same amount of reserves. Under the 2006 Basel II agreement, regulators can thus allow an institution to use credit ratings from certain approved agencies when calculating its net capital reserve requirements. More recently, some related market instruments, such as the price of credit default swaps (Oliver Hart and Luigi Zingales 2009) or the difference between the Libor rate and the overnight swap rate (John Taylor and John Williams 2009), 
have been proposed as alternatives or complements to achieve the same goal. All these schemes (including those based on the so-called "value-at-risk") have merits and defects: the price of credit default swaps (CDS), for instance, reflects in principle the probability a given institution is insolvent, but the CDS market is believed by many to be rather thin and subject to distortions. A regulator who prefers to be eclectic on the matter could use our framework as follows. ${ }^{20}$ In the above language, consider each valuable source of warnings about a given financial institution - credit rating agencies, credit default swaps, etc. - as if it were a particular "model" $m_{i}$, and the corresponding ratings or prices at a given time as a "scenario" $\omega_{i}$. Scenarios from any model clearly depend on the same policy variable: the institution's current capital reserves. Policy triggers are now captured by the functions $u_{i}\left(\omega_{i}\right)$; to render Hart and Zingales $(2009$, p. 14)'s suggestion, for example, if $\omega_{i}$ stands for CDS prices over the last 30 trading days, then $u_{i}\left(\omega_{i}\right)$ might be negative when those prices were above some pre-specified threshold for at least 20 days. Let $\pi\left(\ldots u_{i}\left(\omega_{i}\right) \ldots\right)$ measure the policymakers' joint degree of apprehension about the institution's financial health and its (possibly systemic) consequences, based on the available scenarios and triggers. Taking $\mathrm{v}=-\pi \circ U$ as the criterion to assess ex post scenarios, capital requirements which are (in theory, at least) robust, consistent, holistic and effective (the latter ensuring that the financial institution is solvent with probability one) could finally be set by solving equation (1).

\footnotetext{
${ }^{20}$ Of course, policymakers might as well pay less attention to seeking preventive trigger mechanisms and center instead on some capital insurance scheme to mitigate the costs of a crisis (as proposed by Anil Kashyap et al. 2008).
} 
Several issues must naturally be dealt with before such conclusions are guaranteed to hold in practice. First, one needs to understand how political and strategic factors could distort the observed assessments and declared willingness-to-pay. Given its influence on policy design, the set of relevant models might also be manipulated by some interested parties. Handling these concerns satisfactorily will require extending the present teamtheoretic context to a strategic multiple-player one. ${ }^{21}$ Secondly, one must be able to systematically find the functions $U, \mathrm{v}$, and $\pi$. The first one might again be inherent to the policy mechanism (as in the example of the previous paragraph). The latter might be directly elicited from policymakers, using for example some form of prediction market (Justin Wolfers and Eric Witzewitz 2004), or estimated thanks to some recent advances in computer simulation (Joshua Epstein and Robert Axtell 1996). Last, one ought to analyze a dynamic version of the current scheme which allows models to evolve and policymakers to learn, something proponents of model averaging or the ambiguity criteria have already done (see, e.g., Larry Epstein and Martin Schneider 2007). A first step in this direction would be to consider what happens to the policy rule $\Phi$ when the set of scenarios $\Omega$ shrinks or expands. At some point, the true scenario might not even be among those supplied. This case remains a puzzle for the Bayesian and ambiguity approaches, which rely on probability distributions. Our method, however, might adequately come to terms with it because beliefs concerning whether at least one forecast can be trusted can be embedded in the shadow price $\pi$. This point calls again for further investigation.

\footnotetext{
${ }^{21}$ The classical theory of economic policy has already been taken in this direction by Acocella and Di Bartolomeo (2006).
} 


\section{References}

Acocella, Nicolas, and Giovanni Di Bartolomeo. 2007. "Toward a New Theory of Economic Policy: Continuity and Innovation." Mimeo, University of Teramo.

Acocella, Nicolas, and Giovanni Di Bartolomeo. 2006. "Tinbergen and Theil Meet Nash: Controllability in Policy Games." Economics Letters, 90: 213-218.

Aragonès, Enriqueta, Itzhak Gilboa, Andrew W. Postlewaite, and David Schmeidler. 2005. "Fact-Free Learning." American Economic Review, 95(5): 1355-1368.

Bankes, Steve. 1993. "Exploratory Modeling for Policy Analysis," Operations Research, 41(3): 435-449.

Barrieu, Pauline, and Bernard Sinclair-Desgagné. 2006. "On Precautionary Policies," Management Science, 52(8): 1145-1154.

Billot, Antoine, Itzhak Gilboa, Dov Samet, and David Schmeidler. 2005. "Probabilities as Similarity-Weighted Frequencies." Econometrica, 73(4): 1125-1136.

Brainard, William C. 1967. "Uncertainty and the Effectiveness of Policy." American Economic Review, 57(2): 411-425.

Brock, William A., Steven N. Durlauf, and Kenneth D. West. 2003. "Policy Evaluation in Uncertain Economic Environments." Brookings Papers on Economic Activity, 2003(1): 235-301.

Chamberlain, Gary. 2000. "Econometrics and Decision Theory." Journal of Econometrics, 95(2): 255-283.

Chen, Zengjin, and Larry Epstein. 2002. "Ambiguity, Risk, and Asset Returns in Continuous Time," Econometrica, 70(4): 1403-1443.

Clarida, Richard, Jordi Gali, and Mark Gertler. 1999. "The Science of Monetary Policy: a New-Keynesian Perspective." Journal of Economic Literature, 37: 1661-707.

Cooley, Thomas, ed. 1995. Frontiers of Business Cycle Research. Princeton, NJ: Princeton University Press.

Cont, Rama. 2006. "Model Uncertainty and its Impact on the Pricing of Derivative Instruments," Mathematical Finance, 16(3): 519-547.

Craven, Bruce D. 1972. "Nonlinear Programming in Locally Convex Spaces." Journal of Optimization Theory and Applications, 10(4): 197-210.

Cripps, Martin W., Jeffrey C. Ely, George J. Mailath, and Larry Samuelson. 2008. "Common Learning." Econometrica, 76(4): 909-933.

Davey, Brian A., and Hilary A. Priestley. 2002. Introduction to Lattices and Order (second edition). Cambridge, UK: Cambridge University Press.

Eggertsson, Thráinn. 1997. "The Old Theory of Economic Policy and the New Institutionalism." World Development, 25(8): 1187-1203. 
Ellsberg, Daniel. 1961. "Risk, Ambiguity, and the Savage Axioms," Quarterly Journal of Economics, 75 (4): 643-669.

Epstein, Joshua M., and Robert Axtell. 1996. Growing Artificial Societies: Social Sciences from the Bottom Up. Cambridge, MA: MIT Press.

Epstein, Larry G., and Martin Schneider. 2007. "Learning under Ambiguity," Review of Economic Studies, 74: 1275-1303.

Fernandez, Carmen, Eduardo Ley, and Mark F. J. Steel. 2001. "Benchmark Priors for Bayesian Model Averaging," Journal of Econometrics, 100: 381-427.

Friedman, Milton. 1968. "The Role of Monetary Policy," American Economic Review, 58(1): 1-17.

Garlappi, Lorenzo, Raman Uppal, and Tan Wang. 2007. "Portfolio Selection with Parameter and Model Uncertainty: A Multi-Prior Approach," Review of Financial Studies, 20(1): 41-81.

Gilboa, Itzhak, Andrew Postlewaite, and David Schmeidler. 2008. "Probability and Uncertainty in Economic Modelling." Journal of Economic Perspectives, 22(3): 173-188.

Gilboa, Itzhak, and David Schmeidler. 1989. "Maximin Expected Utility with Non Unique Prior," Journal of Mathematical Economics, 18: 141-153.

Hansen, Lars Peter, and Thomas J. Sargent. 2001. "Robust Control and Model Uncertainty." American Economic Review, 91(2): 60-66.

Hansen, Lars Peter, and Thomas J. Sargent. 2008. Robustness. Princeton, NJ: Princeton University Press.

Hart, Oliver, and Luigi Zingales. 2009. "A New Capital Regulation for Large Financial Institutions," mimeo, Harvard University.

Heal, Geoffrey. 2008. "Climate Economics: A Meta-Review and Some Suggestions for Future Research." Review of Environmental Economics and Policy, published online at http://reep.oxfordjournals.org/cgi/content/short/ren014v1.

Hope, Christopher. 2006. "The Marginal Impact of $\mathrm{CO}_{2}, \mathrm{CH}_{4}$ and $\mathrm{SF}_{6}$ Emissions," Climate Policy, 6(5): 537-544.

Hughes Hallett, Andrew J. 1989. "Econometrics and the Theory of Economic Policy: The Tinbergen-Theil Contributions 40 Years On." Oxford Economic Papers, 41(1): 189-214.

Kashyap, Anil K., Raghuran G. Rajan, and Jeremy C. Stein. 2009. "Rethinking Capital Regulation," Paper prepared for Federal Reserve Bank of Kansas City symposium on Maintaining Stability in a Changing Financial System, Jackson Hole, Wyoming, August 21-23, 2008, published online at http://www.tinbergen.nl/ti-events/tilectures2009/kashyap.pdf.

Klibanoff, Peter, Massimo Marinacci, and Sujoy Mukerji. 2005. "A Smooth Model of Decision Making under Ambiguity," Econometrica, 73(6): 1849-1892. 
Leeper, Eric M., and Thomas J. Sargent. 2003. "[Policy Evaluation in Uncertain Economic Environments]. Comments and Discussion." Brookings Papers on Economic Activity, 2003(1): 302-322.

Lempert, Robert J., Steven W. Popper, and Steven C. Bankes. 2003. "Shaping the Next One Hundred Years - New Methods for Quantitative, Long-Term Policy Analysis," RAND Pardee Center publication.

Levin, Andrew T., and John C. Williams. 2003. "Robust Monetary Policy with Competing Reference Models," Journal of Monetary Economics, 50: 945-975.

Maccheroni, Fabio, Massimo Marinacci, and Aldo Rustichini. 2006. "Ambiguity Aversion, Robustness, and the Variational Representation of Preferences," Econometrica, 74(6): 14471498.

Manne, Alan, Robert Mendelsohn, and Richard Richels. 1995. "MERGE - A Model for Evaluating Regional and Global Effects of GHG Reduction Policies," Energy Policy, 23(1): $17-34$.

Manski, Charles F. 2001. "Identification Problems and Decisions under Ambiguity: Empirical Analysis of Treatment Response and Normative Analysis of Treatment Choice." Journal of Econometrics, 95(2): 415-442.

Nordhaus, William D. 1994. Managing the Global Commons. The Economics of Climate Change. Cambridge, MA: MIT Press.

Nordhaus, William D., and Joseph G. Boyer. 2000. Warming the World: Economic Models of Global Warming. Cambridge, MA: MIT Press.

Nordhaus, William D., and Zili Yang. 1996. "A Regional Dynamic General-Equilibrium Model of Alternative Climate-Change Strategies." American Economic Review, 86(4): 741765 .

Raftery, Adrian E., David Madigan, and Jennifer A. Hoeting. 1997. "Bayesian Model Averaging for Linear Regression Models." Journal of the American Statistical Association, 92(437): 179-191.

Roseta-Palma, Catarina, and Anastasios Xepapadeas. 2004. "Robust Control in Water Management." Journal of Risk and Uncertainty, 29(1): 21-34.

Sims, Christopher A. 2002. "The Role of Models and Probabilities in the Monetary Policy Process." Brookings Papers on Economic Activity, 2002(2): 1-40.

Stern, Nicholas. 2008. "The Economics of Climate Change," American Economic Review, 98(2): 1-37.

Stern, Nicholas. 2007. The Economics of Climate Change: The Stern Review. Cambridge, UK: Cambridge University Press.

Taylor, John B. 1993. "Discretion versus Policy Rules in Practice." Carnegie-Rochester Conference Series on Public Policy, 39: 195-214. 
Taylor, John B., and John C. Williams. 2009. "A Black Swan in the Money Market," American Economic Journal: Macroeconomics, 1(1): 58-83.

Tinbergen, Jan. 1952. On the Theory of Economic Policy (sixth printing). Amsterdam, North Holland Publishing Company.

van Velthoven, Ben C. J. 1990. "The Applicability of the Traditional Theory of Economic Policy." Journal of Economic Surveys, 4(1): 59-88.

Walsh, Carl E. 2004. "Precautionary Policies," Federal Reserve Bank of San Francisco Economic Letter, 2004-05: 1-2.

Wittgenstein, Ludwig. 1922. Tractatus Logico-Philosophicus. London: Routledge and Kegan Paul Ltd.

Wolfers, Justin, and Eric Zitzewitz. 2004. "Prediction Markets," Journal of Economic Perspectives, 18(2): 107-126.

Woodford, Michael. 2003. Interest and Prices: Foundations of a Theory of Monetary Policy. Princeton, NJ: Princeton University Press. 


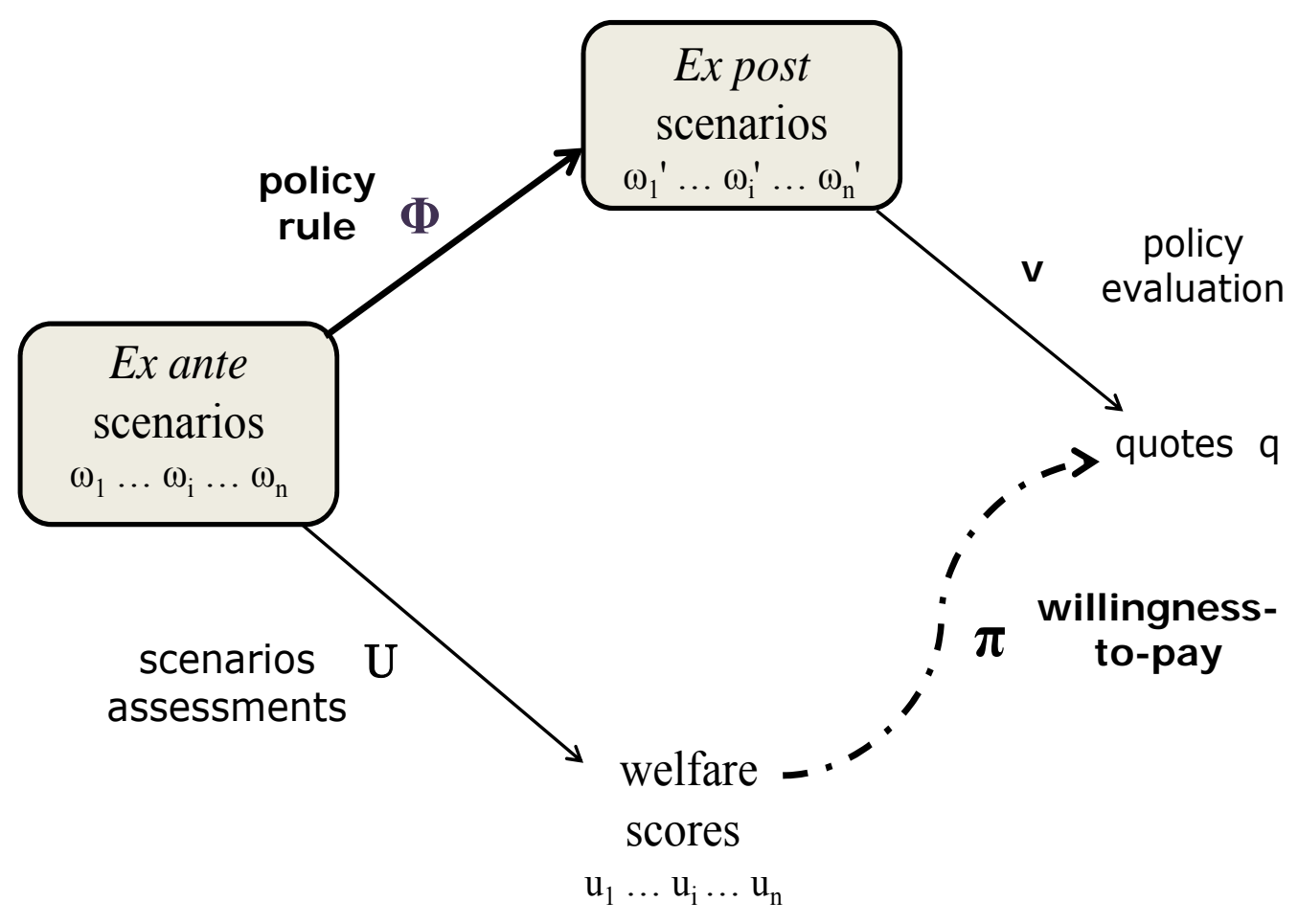

Fiqure 1. The basic construction 


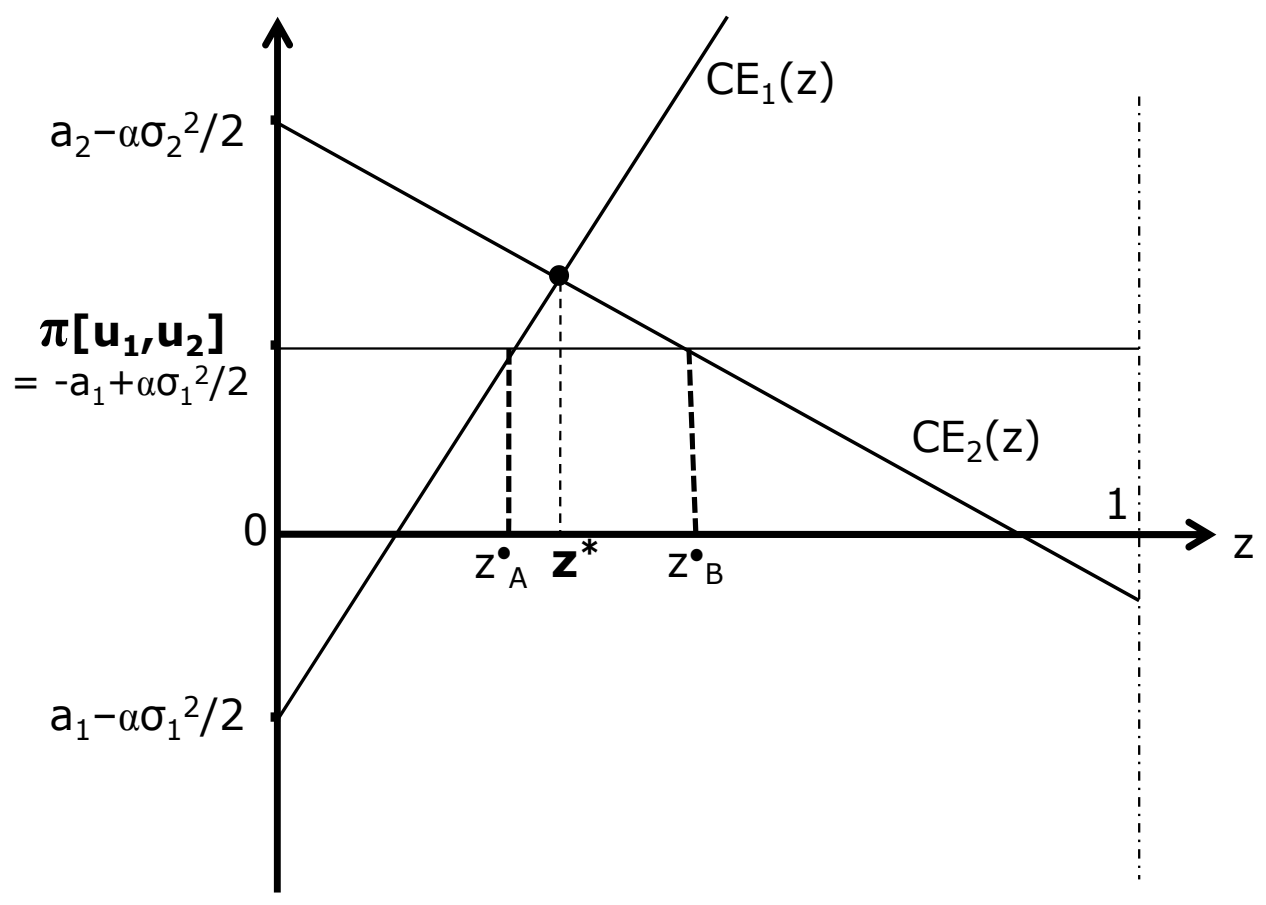

Figure 2. The maximin and this paper's solutions 